See discussions, stats, and author profiles for this publication at: https://www.researchgate.net/publication/328970163

\title{
Developing an Algorithm to Assess the UV Erythemal Dose for Outdoor Workers
}

Conference Paper · June 2018

DOI: 10.1109/EEEIC.2018.8494540

CITATIONS

3

9 authors, including:

\section{Massimo Borra}

INAIL Istituto Nazionale per l'Assicurazione contro gli Infortuni sul Lavoro 41 PUBLICATIONS 398 CITATIONS

SEE PROFILE

Luca Gugliermetti

Sapienza University of Rome

19 PUBLICATIONS 37 CITATIONS

SEE PROFILE
READS

76

Chiara Burattini

Sapienza University of Rome 33 PUBLICATIONS 198 CITATIONS

SEE PROFILE

(2) Alessandro Mangione

Sapienza University of Rome

8 PUBLICATIONS 18 CITATIONS

SEE PROFILE

Some of the authors of this publication are also working on these related projects:

Systematic reviews for the WHO/ILO joint methodology for estimating the work-related burden of disease and injury View project

PEROSH, IndIRUV View project 


\title{
Developing an algorithm to assess the UV erythemal dose for outdoor workers
}

\author{
Validation through direct measures
}

\author{
Massimo Borra, Carlo Grandi, Andrea Militello \\ Department of Occupational and Environmental Medicine, \\ Epidemiology and Hygiene \\ INAIL \\ Monte Porzio Catone, Italy \\ m.borra@inail.it, ca.grandi@inail.it, a.militello@inail.it
}

\author{
Chiara Burattini, Luca Gugliermetti, Alessandro \\ Mangione, Fabio Bisegna \\ Department of Astronautic, Electric and Energy Engineering \\ Sapienza University \\ Rome, Italy \\ chiara.burattini@uniroma1.it, \\ luca.gugliermetti@uniroma1.it, fabio.bisegna@uniroma1.it
}

\author{
Alberto Modenese, Fabriziomaria Gobba \\ Department of Biomedical, Metabolic and Neural Science \\ University of Modena and Reggio Emilia \\ Modena, Italy \\ alberto.modenese@unimore.it, fabriziomaria.gobba@unimore.it
}

\begin{abstract}
An algorithm has been developed to determine the annual dose of UV solar radiation for outdoor workers. The dose is indirectly assessed basing on satellite data, mean global irradiance values, workers' data obtained by means of a questionnaire and corrective coefficients provided by a mathematical model. The values obtained by the use of the algorithm are compared with those obtained by measurement records in different environments. Results demonstrated that the algorithm estimates the mean daily erythemal dose with good approximation.
\end{abstract}

Keywords— solar radiation; outdoor workers; UV dose; satellite data; questionnaire.

\section{INTRODUCTION}

Solar Radiation (SR) may have acute and long-term adverse effects on both skin and eye, mainly due to the UV component [1]. The skin effects include, but are not restricted to, erythema (the common skin reddening due to sunburn), non-melanoma skin cancers (NMSC), such as basal cell carcinoma and squamous cell carcinoma, and malignant melanoma; photokeratitis and photoconjunctivitis are inflammatory reaction of the eye caused by UV radiation, while cataract is a widespread long-term eye effect.

Outdoor workers are significantly exposed to solar UV radiation, but exposure is highly variable, depending on environmental, occupational and personal features. The UV radiation arriving at the ground depends on sun elevation, latitude, altitude, ozone layer and sky conditions; the amount of UV radiation reaching the human body is highly affected by albedo: the reflectance of several common outdoor ground materials is reported in Table I [2].

This work is part of the BRIC project and it has been realized with the INAIL financial support.
TABLE I. TYPICAL REFLECTANCE OF SEVERAL GROUND MATERIALS

\begin{tabular}{|c|c|}
\hline \multicolumn{2}{|c|}{ Albedo } \\
\hline Material & Reflectance \\
\hline Asphalt & $5-9 \%$ \\
\hline Cement (wet) & $55 \%$ \\
\hline Concrete & $8-12 \%$ \\
\hline Grass & $0.8-3.7 \%$ \\
\hline Sand (dry) & $15-18 \%$ \\
\hline Sand (wet) & $7 \%$ \\
\hline Snow (fresh) & $88 \%$ \\
\hline Snow (dirty) & $59 \%$ \\
\hline
\end{tabular}

Clothing and accessories like hats and sunglasses, as well as sunscreens, reduce the effective exposure of the tissues; in addition shading can reduce to more than $50 \%$ the exposure of outdoor workers to SR. The skin type (photo-type) affects both the skin ability to adapt to SR and the occurrence of adverse effects: the Fitzpatrick's photo-types I and II require higher protection, while photo-types $\mathrm{V}$ and VI are less UV sensitive due to higher melanin content; nevertheless darker photo-types need protection as well since they are not exempt from skin cancer risk. European Directive 2006/25/CE [4] established a limit value for daily exposure to the whole UV radiation equal to $30 \mathrm{~J} / \mathrm{m}^{2}$ over a period of 8 hours; nevertheless past studies clearly showed that this value can be exceeded in outdoor workers [5][6]. In particular, farmers, sea workers and construction workers resulted to be the categories with higher UV exposure values [7]. 
The poor attention paid by employers to this risk translates into an insufficient prevention. Moreover, it introduces concerns if a causal relationship between skin cancer occurred in a worker and his/her past long-term exposure to SR has to be assessed retrospectively. This item is even more difficult to address if a malignant melanoma of the skin occurs in body districts which were less exposed to direct SR.

Individual exposure may be measured by using personal dosimeters, but presently technical limitations and/or operative concerns may reduce or even prevent their usage in a lot of cases. Moreover, the recently developed sensors for estimating the UV index (UVI) do not perform accurate measures of body exposure to SR [8].

Several indirect methods to assess UV exposure of outdoor workers have been proposed, with no general agreement. In addition, there may be need to assess lifetime cumulative exposure of an individual worker for both epidemiological and legal purposes.

An algorithm for assessing the annual UV dose based on an indirect method developed by some of the authors was described elsewhere [9]; the aim of this work is to validate this algorithm by means of direct measures of UV solar radiation.

\section{ALGORITHM}

An indirect method for estimating the average annual effective UV dose $\left(E_{h}\right)$ received by a specific body area/district has been defined previously [9][10]. For a given area/district it takes into account: the exposure time, the average effective irradiance reaching the tissue, the local mean monthly effective horizontal radiant exposure, the albedo of the surrounding surfaces/objects and the use of protective clothes and accessories.

This method is indirect since it does not require a continuous monitoring of the individual worker exposure to solar UV radiation, but it is based on both database values and information provided by the workers: the actual solar irradiation level is derived from satellite data and scientific GIS databases [11], while the worker's related data (workplace, job, working time and schedule, clothing and other protections) are provided by means of a questionnaire filled by the worker itself.

Basing on these data an algorithm has been developed to assess the annual dose of solar UV radiation related to the worker. The mean radiant exposure related to a given month in a selected location was derived from satellite data (TEMISESA) [12] and the mean global irradiance over the same period was provided by ENEA [13] on the basis of measured data; both data sets consider the cloudy coverage and the ozone column, and the satellite data are the average value over a period of five years. The ratio of these two values gives a coefficient for estimating the mean erythemal dose of one month on the horizontal plane; adjustments relative to the number of working hours and days, clothing, albedo and position of the exposed body district were successively applied.

\section{MEASUREMENTS AND DATA ANALYSIS}

Several direct measures of SR have been carried out to calculate the solar exposure in terms of effective UV dose ( $\left.E_{\text {eff }}\right)$ related to the measurement conditions.

Spectroradiometric and dosimetric measurements have been performed in three outdoor environments having different albedo: a cloister inside Rome has been selected as city site (C), the hills of Monte Porzio Catone, a little town near Rome, was the countryside setting $(\mathrm{H})$ and the beach of Ostia, a seaside along the coast of Rome, represented the sandy conditions $(\mathrm{B})$. The following Table 2 provides information concerning the three measurements settings.

TABLE II. MEASUREMENT SETTINGS FEATURES

\begin{tabular}{|c|c|c|c|}
\hline \multirow{2}{*}{$\begin{array}{c}\text { Solar Radiation } \\
\text { Measures }\end{array}$} & \multicolumn{3}{|c|}{ Setting } \\
\hline & Beach (B) & City (C) & Hill $(H)$ \\
\hline Location & Ostia & Rome & $\begin{array}{c}\text { Monte Porzio } \\
\text { Catone }\end{array}$ \\
\hline Latitude & $41^{\circ} 43^{\prime} \mathrm{N}$ & $41^{\circ} 53^{\prime} \mathrm{N}$ & $41^{\circ} 49^{\prime} \mathrm{N}$ \\
\hline Longitude & $12^{\circ} 16^{\prime} \mathrm{E}$ & $12^{\circ} 28^{\prime} \mathrm{E}$ & $12^{\circ} 43^{\prime} \mathrm{E}$ \\
\hline Altitude (m) & 0 & 21 & 451 \\
\hline Day & 16th Dec & 15th Dec & 20th Apr \\
\hline Sky condition & $\begin{array}{l}\text { sunny } \\
\text { (little clouds) }\end{array}$ & sunny & variable \\
\hline
\end{tabular}

The horizontal spectral irradiance $\left(E_{\lambda}\right)$ has been measured by means of the Avantes spectroradiometer, having 175-1160 nm interval, and the UV erythemal weighted irradiance $\left(E_{\mathrm{s}}\right)$ has been measured by means GigaHertz Data-Logger UV dosimeters. The measurements have been performed on a horizontal surface $1 \mathrm{~m}$ above the ground, from the 11:00 a.m. to the 3:00 p.m., with an interval of 10 minutes for the spectral measures and 1 minute for the dosimeters measures. Different sky conditions occurred in the measurement days: completely clear sky with sun during the whole measurement period in $C$, clear sky with the presence of clouds over the sun in a limited interval of measure in B and completely variable conditions in $\mathrm{H}$.

The measured data have been post processed for obtaining the $\mathrm{E}_{\text {eff }}$ corresponding to the solar exposure in the different measurement conditions: $\mathrm{E}_{\text {eff }}$ has been calculated according to the procedure defined by the International Commission of Non Ionizing Radiation Protection (ICNIRP) [2]. Dosimeters results provided the erythemal weighted irradiance $\left(E_{s}\right)$, while, in order to obtain the corresponding $E_{s}$ from spectral data, each irradiance spectrum provided by the spectroradiometer has firstly weighted with the ultraviolet hazard weighting function $\mathrm{S}_{\mathrm{UV}}$, defined by the International Commission on Illumination [14], using the equation

$$
\mathrm{E}_{\mathrm{S}}=\sum_{250}^{400} E_{\lambda} S_{\mathrm{UV}} \Delta \lambda
$$


The $E_{\text {eff }}$ was obtained multiplying the $E_{s}$, either measured with dosimeters or calculated as in (1), for the measurement interval: 60 and 600 seconds respectively in the case of dosimeters and calculated from spectral results. In order to define the total UV erythemal dose corresponding to the exposure time $(\mathrm{T})$, the integrated value from 11:00 am to 3:00 pm of the $\mathrm{E}_{\text {eff }}$ was calculated.

Also the UVI corresponding to the individual measures of irradiance has been calculated from spectral measures with the equation 2:

$$
\mathrm{UVI}=\mathrm{k}_{\mathrm{er}} \mathrm{Es}
$$

Where $\mathrm{k}_{\mathrm{er}}$ is a constant equal to $40 \mathrm{~m}^{2} / \mathrm{W}$.

\section{RESULTS}

The UV spectral irradiance measured in the three settings at 1:00 pm has showed in the graph of figure 1.

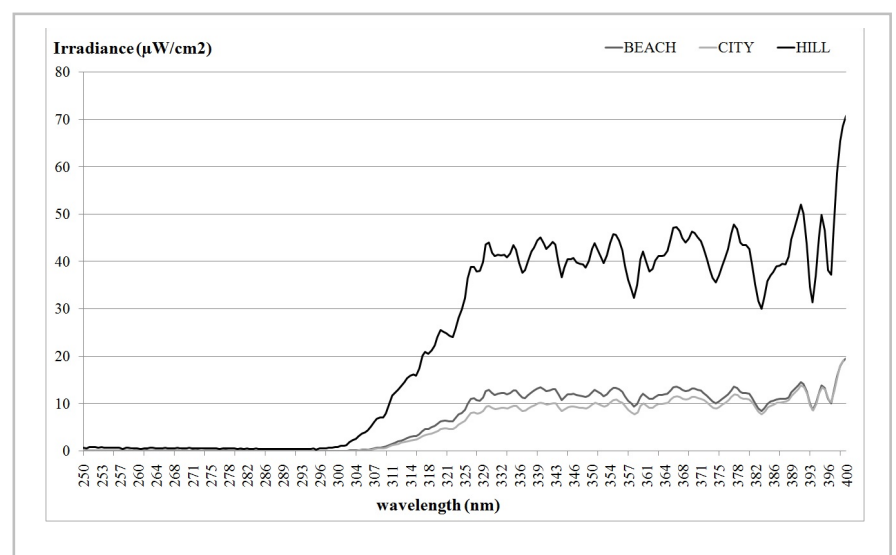

Fig. 1. Spectral irradiance measured at 1:00 pm

The measured irradiance levels differ according to the location features and the month of acquisition; the measures in the $\mathrm{H}$ setting have been carried out in April and for this reason the irradiance in the UV band, as well as the total solar irradiance, are higher than those recorded in December in the other two settings. The difference in the $\mathrm{B}$ and $\mathrm{C}$ graphs is not due to the weather conditions, since both measures have been carried out under clear sky with sun, but it is related to the environment itself: the B setting is a seaside and the measures are carried out in the beach, while the $\mathrm{C}$ setting is a cloister inside the city. The sky factor was likely to determine the higher amount of UV irradiation in $\mathrm{B}$ with respect to the $\mathrm{C}$ setting, as well as the wall reflectance caused higher irradiation level in the visible band. Despite these differences all the three graphs have values close to zero below the $300 \mathrm{~nm}$ : what has been recorded by the spectroradiaometer is only background noise, since the atmosphere completely filters these UV radiations and nothing arrives on the Earth.

These data are also confirmed by dosimeters records showed in Figure 2. In December the $E_{s}$ is maximal from 11 am to $12: 30 \mathrm{pm}$, then its level decreases rapidly; while in May the variable sky conditions caused the continuous increase and decrease of the irradiance level and then of the erythemal irradiance.

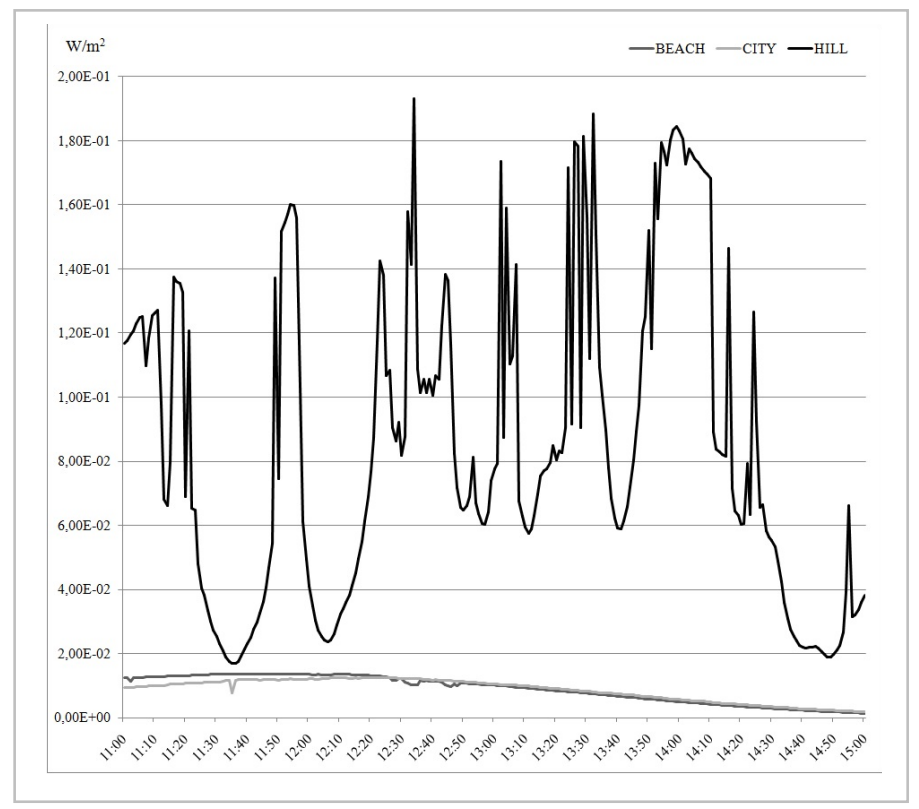

Fig. 2. Erythemal weighted irradiance measured with dosimeters from 11 am to $3 \mathrm{pm}$ in the three settings

The $E_{s}$ values in the $B$ and $C$ settings are basically the same and, in fact, the curves are overlapped for almost all the measurement time; the only exception is the interval from $12: 20$ to $12: 50$ when the presence of an isolated cloud that temporary covered upon the sun caused little drops in the B curve.

The calculated UVI relative to the single spectral measurements from 11:00 am to $2: 50 \mathrm{pm}$ in each day of investigation are showed in Table III.

TABLE III. UV INDEX CALCULATED FROM SPECTRAL IRRADIANCE

\begin{tabular}{|c|c|c|c|c|c|c|c|}
\hline \multicolumn{8}{|c|}{ UVI } \\
\hline $\begin{array}{l}\text { hour } \\
\text { (am) }\end{array}$ & (B) & (C) & (H) & $\begin{array}{l}\text { hour } \\
(\mathrm{pm})\end{array}$ & (B) & (C) & (H) \\
\hline $11: 00$ & 0.9 & 0.7 & 4.7 & $1: 00$ & 0.7 & 0.5 & 5.2 \\
\hline $11: 10$ & 0.9 & 0.7 & 5 & $1: 10$ & 0.6 & 0.5 & 2.3 \\
\hline $11: 20$ & 1 & 0.8 & 2.6 & $1: 20$ & 0.6 & 0.5 & 3.1 \\
\hline $11: 30$ & 1 & 0.8 & 1.1 & $1: 30$ & 0.5 & 0.4 & 6.9 \\
\hline $11: 40$ & 0.9 & 0.9 & 1 & $1: 40$ & 0.5 & 0.4 & 2.3 \\
\hline $11: 50$ & 0.9 & 0.8 & 4.2 & $1: 50$ & 0.4 & 0.4 & 4.3 \\
\hline $12: 00$ & 0.9 & 0.7 & 1.7 & $2: 00$ & 0.4 & 0.3 & 6.9 \\
\hline $12: 10$ & 0.9 & 0.7 & 1.3 & $2: 10$ & 0.3 & 0.3 & 6.5 \\
\hline $12: 20$ & 0.8 & 0.7 & 2.9 & $2: 20$ & 0.3 & 0.3 & 2.4 \\
\hline $12: 30$ & 0.8 & 0.6 & 3.1 & $2: 30$ & 0.2 & 0.3 & 2.2 \\
\hline $12: 40$ & 0.7 & 0.6 & 3.8 & $2: 40$ & 0.2 & 0.2 & 0.9 \\
\hline $12: 50$ & 0.8 & 0.6 & 2.5 & $2: 50$ & 0.1 & 0.2 & 0.9 \\
\hline
\end{tabular}


The UVIs reflect the radiant exposure in each condition. B and $\mathrm{C}$ have similar UVIs since the measures have been carried out in similar weather conditions and consecutive days; the higher levels in B are due to the seaside sky factor and sand albedo. Nevertheless, in both cases, the low UVI allows a safe exposure without any protection during the entire day. In $\mathrm{H}$ the UVI is generally higher with respect to the other two conditions, since the measures were carried out in April, when the irradiation level is higher than in January; the continuous oscillation of the UVI reflects the high variability of the weather conditions in $\mathrm{H}$ setting: values close to 1 correspond to covered sky, for UVI $>4$ the solar radiation was little filtered by clouds and for intermediate values the sun was partially covered by clouds.

\section{ALGORITHM-MEASUREMENT COMPARISON}

The calculation of the UV erythemal dose was repeated using the algorithm developed: it was calculated separately for each site $(\mathrm{B}, \mathrm{C}$ and $\mathrm{H})$ on a horizontal surface exposed from 11:00 am to $15: 00 \mathrm{pm}$.

The input data was referred to the three measured days and settings. The algorithm requires to set the month, the day and the hours of exposure for identifying the exposure time, the latitude, longitude and altitude of the locality for acquiring the corresponding irradiation level and the indication of the environment contex (beach, city, hill) for correcting the irradiation value with the sky factor and albedo. Additionally information about the clothing, sunglasses, hat and sunscreen use can be set, but these personal protections were excluded from the calculation since they were not considered in the measurement campaign.

The algorithm acquires the reference values of radiation from databases provided by two agencies: ENEA provides for each month the mean global irradiance at the ground for a selected locality and TEMIS gives the corresponding radiant exposure.

Table IV shows the resulting UV doses for the 4 hours of exposure in the three sites of investigation, as calculated on the basis of the spectral measures, as well as with the algorithm, together with the difference in percentage between the two values. Results reported in Table IV indicate that the algorithm has different performances, depending on both the setting and the weather conditions: in fact it overestimated the dose relative to the $\mathrm{B}$ setting and underestimated the doses of $\mathrm{C}$ and H.

TABLE IV. COMPARISON BETWEEN UV DOSE MEASUREMENTS AND ALGORITHM CALCULATION

\begin{tabular}{|l|c|c|c|}
\hline \multirow{2}{*}{\multicolumn{1}{|c|}{ Dose $\left(\mathbf{J} / \mathbf{m}^{2}\right)$}} & \multicolumn{3}{c|}{ Setting } \\
\cline { 2 - 4 } & Beach $(\boldsymbol{B})$ & City $(\boldsymbol{C})$ & Hill $(\boldsymbol{H})$ \\
\hline spectral irradiance & 238 & 191 & 1134 \\
\hline algorithm & 261 & 160 & 937 \\
\hline difference & $9 \%$ & $16 \%$ & $17 \%$ \\
\hline
\end{tabular}

The predictive ability of the algorithm will be tested in other environments with respect to beach, city, and hill, with the purpose of verifying its capacity of assessing altitude, albedo and sky factor: a particular environmental condition is high mountain with snow, since the exposure evaluation is very complicated for the reduced ozone layer and the high UV reflectance of the snow.

Finally, this study considered the irradiation level on a horizontal surface, that could reproduce the exposure of few body districts, like the top of the head, the upper shoulders or 
the foots; the future measurement campaigns will detect the exposure level in different body areas, with the aim of testing the algorithm in its ability of assessing the erythemal dose in body districts with different orientations.

\section{REFERENCES}

[1] World Health Organization (WHO), Environmental burden of deseases series $n^{\circ} 17$. Solar Ultraviolet radiation, Geneva, 2010.

[2] International Commission on Non Ionizing Radiation Protection. ICNIRP Statement - "Protection of workers against ultraviolet radiation". Health Phys 2010;99(1):66-8

[3] International Agency for Research on Cancer (IARC), Radiation Volume 100 D. A review of human carcinogens, Lyon, France, 2002.

[4] Directive 2006/25/EC of the European Parliament and of the Council "on the minimum health safety requirements regarding the exposure of workers to risks arising from physical agents (artificial optical radiation)" 5 April 2006

[5] A.M. Siani, G.R. Casale, R. Sisto, A. Colosimo, C.A. Lang, M.G. Kimlin, "Occupational Exposures to Solar Ultraviolet Radiation of Vineyard Workers in Tuscany (Italy)", Photochem Photobiol, 2011, 87, pp. 925-934.

[6] M.A. Serrano, J. Cañada, J.C. Moreno, "Erythemal Ultraviolet Exposure in two Groups of Outdoor workers in Valencia, Spain", Photochem Photobiol, 2009, 85, pp.1468-1473.

[7] European Agency for Safety and Health at Work. Outlook 1 New and emerging risks to occupational safety and health. Luxemburg: Publications Office of the European Communities, 2009.
[8] A. Militello; M. Borra; F. Bisegna; C. Burattini; C. Grandi "Smart Technologies: Useful Tools to Assess the Exposure to Solar Ultraviolet Radiation for General Population and Outdoor Workers", 18th Italian National Conference on Photonic Technologies (Fotonica 2016), 6-8 June 2016, Rome, Italy, p. 85.

[9] A. Modenese, F. Bisegna, M. Borra, C. Grandi, F. Gugliermetti, A. Militello, F. Gobba, " Assessing the Cumulative Solar Radiation Exposure among Outdoor Workers: Presentation of a Method for Epidemiological Studies", 5th International Conference on Electromagnetic Fields, Health and Environment, Oporto, Portugal, 24th-26th May, 2014.

[10] A. Modenese, F. Bisegna, M. Borra, C. Grandi, F. Gugliermetti, A. Militello, F. Gobba, "Outdoor work and solar radiation exposure: evaluation method for epidemiological studies", Medycyna Pracy, 2016, 67, pp. 577-587.

[11] D. Groppi, L. de Santoli, F. Cumo, D. Astiaso Garcia, "A GIS-based model to assess buildings energy consumption and usable solar energy potential in urban areas", Sustainable Cities and Society, in press.

[12] http://www.temis.nl

[13] ENEAhttp://www.solaritaly.enea.it/CalcRggmmOrizz/Calcola1.php

[14] International Commission on Illumination, "Erythema reference action spectrum and standard erythema dose", CIE S007/E:1998.

World Health Organization, World Meteorological Organization, United Nations Environment Programme, International Commission of NonIonizing Radiation Protection, "Global Solar UV Index: A Practical Guide", Geneva, Switzerland, 2002. 